\title{
Difficulties and Solutions for Social Integration of Disabled Children
}

\author{
Tingyu Luo, a
}

\author{
${ }^{1}$ The University of the South, Sewanee, TN 37383-2000 \\ aluot0@sewanee.edu
}

\begin{abstract}
The social integration level of disabled children determines their process of achieving self-worth and pursuing a better life. The difficulties of social integration of disabled children are mainly manifested in the neglect of the right to social participation, the inadequate protection of the right to education and the exclusion of the living environment. The combination of subjective psychological factors and objective social factors is the cause of social integration difficulties for disabled children. Therefore, concept education and publicity should be strengthened; relevant laws and supporting systems should be improved; Archival information management should be done well; Community rehabilitation management should be strengthened; besides, disabled children should be helped to integrate into the society.
\end{abstract}

Keywords: Disabled children, Social integration, Social participation, Right system

\section{INTRODUCTION}

Children are the flowers of the motherland, the future of the nation, and a population group that has received much attention from all walks of life. However, due to their own physical defects, disabled children belong to one of the most vulnerable groups in the society and receive far less attention. According to the Communique on Main Data of the Second National Sampling Survey of Disabled People issued by the National Statistics Bureau and the Leading Group for the Second National Sample Survey of Disabled People in May 2007, the total number of disabled people in China is 82.96 million, accounting for $6.34 \%$ of the total population. Among them, the number of disabled children aged $0-14$ is 3.87 million, accounting for $4.66 \%$ of the national disabled population. [1]

The number of disabled children is huge. They are the basic members of the society. They also have the rights and obligations to advance human society. Moreover, they have the desire for interpersonal communication and the ability to realize self-worth [2]. In order to realize their self-worth and yearning for a better life, disabled children should participate in social life and integrate into social development. Childhood is the most important stage for a person to complete the socialization, and disabled children are bound to encounter more difficulties in the process of socialization. How to help them better complete social integration is the focus of this study.

\section{RELATED CONCEPTS}

\subsection{Disabled Children}

Academic circles generally define disabled children in both broad and narrow sense. In the broad sense, disabled children mean the children with significant differences from normal children in intelligence, sensory ability, emotion and behavior development, body or speech, including the children who are developing below normal as well as the children above normal development levels, and the children with minor offenses [3]. In the narrow sense, it refers to the children who are deficient in physical and mental development. The definition of disabled children in this paper tends to be the narrow one, which refers to the children aged 0-14 who are deficient in vision, hearing, speech, body, intelligence, spirit, etc., full or partial loss of self-care ability, learning ability, and social participation ability.

\subsection{Social integration}

"Social integration" is a sociological concept. Generally speaking, the academic concept of "social integration" is based on three paths. The first path is to put the social integration as an important variable of social stability, to explain the social system and social stability process. The second way is to regard social integration as the content of immigration research and as the ultimate goal of immigration development. The third route is to regard social integration as a companion to the concept of social exclusion [4]. This paper mainly takes the third route, 
which regards social integration as the full participation of social groups or individuals under the premise of abiding by social norms and laws, who are not to be isolated and alienated by the society.

\section{LITERATURE REVIEW}

There is little literature devoted to the study on social integration of disabled children but social work has some concerns. In connection with the research, some scholars have studied the social integration of disabled groups; some have studied the social support network of disabled children; besides, some have studied the social development of disabled children.

Liu Lin et al. (2010) used a concept similar to "social integration" - "social inclusion". The meaning of "social inclusion" is to help those individuals or groups that are excluded and disadvantaged to have a position to fully participate in the society in which they live [5]. They advocated using participatory development theories and methods to achieve the social inclusion of disabled people [6].

Zou Jingwei (2014) used the "Sunshine Angel" Project to introduce professional social work methods, which affected subjective self-confidence, emotional handling, and positive outlook on life, and ultimately achieved the goal of disabled children actively participating in society through external factors [7]. Liu Yali (2017) proposed that disabled children could not help themselves out of their life and emotional difficulties only by relying on their families. Social support network could not only help disabled children reduce the burden of life, but also help them relieve psychological pressure and restore confidence in life to a certain extent [8]

$\mathrm{Xu}$ Qiaoxian (2012) cut into the theme from the perspective of social inclusion [9]. She analyzed current main problems of the integration of disabled people in China and put forward relevant suggestions from the perspectives of concept, policy, and action to improve the level of social inclusion and promote the integration of disabled people into society. For example, efforts should be made to cultivate the concept and consciousness of tolerating disabled people, to improve the policy and regulation system for promoting the integration of disabled people into society, and to build a three-in-one support system for disabled people in communities, schools, and families.

An Hongtao et al. (2015) valued the role of community activities. They believed that in the critical period of social development of disabled children, community activities could provide them with the opportunity to experience life experiences. They also could create life-interactive situations and demonstrate the realities of life. Besides, they could help disabled children develop positive social cognition in mutual adaptation with others and the social environment. [10]

\section{DIFFICULTIES IN SOCIAL INTEGRATION OF DISABLED CHILDREN}

\subsection{The right to social participation is neglected}

It is the goal of social integration that disabled children acquire the right to participate in society. Social integration is the basis and prerequisite for obtaining the right to participate in society. The social participation right of disabled children can be defined as the right of disabled children to participate in family, school, community, social life and related affairs. It can be said that the right to social participation of disabled children is the most neglected right among many of their rights.

On the one hand, the right to know and to express of disabled children is in the wrong position. Disabled children are often considered to have no subjective initiative and independent decision-making ability, and their reasonable appeals and subjective opinions are often ignored. As a result, reasonable benefits are not guaranteed On the other hand, disabled children lack sufficient freedom to participate in social activities. Disabled children often receive unfair treatment in arts, culture, sports, and other activities, and are set thresholds artificially without the same treatment as ordinary children.

\subsection{The right to education is not fully guaranteed}

According to the results of the Second National Sampling Survey of Disabled People, the number of disabled children aged 6-14 was 2.46 million, accounting for $2.96 \%$ of the total disabled population. Among the school-age disabled children, $63.19 \%$ are receiving compulsory education in general education or special education schools In other words, the number of school-age disabled children who did not receive education reached 906,000, accounting for $36.81 \%$ of school-age disabled children Compared with the $100 \%$ compulsory education penetration rate of ordinary children, the gap between disabled children and ordinary children is obvious.

In addition to the problem of quantity, there is also a qualitative gap - the education of disabled children faces the difficulty of uneven development. The urban-rural gap and regional gap are the manifestations of education imbalance. Most rural and western cities in China do not have special education schools for disabled children. At present, educational resources are still concentrated in large cities and eastern regions. The lack of access to education for disabled children will inevitably lead to the weakening of social integration ability and deprivation of development opportunities. 


\subsection{Exclusion of living environment}

The living environment is divided into physical space and human space of life. The living environment of disabled children shows certain "exclusion".

The exclusion of physical space is mainly manifested in public facilities, through which disabled children participate in social life. Public facilities for the living of disabled children are different from those for ordinary children, but in many cities, especially in the vast rural areas, public facilities only for disabled children have not been built yet. Even though many barrier-free facilities have been built in some big cities, they still face the situation of unreasonable design and being occupied and abandoned.

The exclusion of human space is more obvious. For example, healthy people in daily life are reluctant to contact disabled people and are unwilling to interact with disabled people. It also shows discrimination and exclusion in education and employment. Most disabled people are still socially marginalized groups, who are neglected, discriminated, and living outside the mainstream society.

\section{REASONS FOR SOCIAL INTEGRATION DIFFICULTIES OF DISABLED CHILDREN}

As a result, disabled children have defects in physical function, physiological function, mental health, and intelligence level, coupled with the lack of legal system and institutional mechanisms. Disabled children, on the one hand, are different from normal children in cognition, emotion, volitional behavior and personality characteristics [11] with feelings of inferiority, sensitivity, and pessimism. Moreover, the social environment has a low degree of social acceptance for disabled children and social exclusion is easy to occur, which in turn affects their social integration ability.

\subsection{Subjective psychological factor}

First, self-enclosure due to inferiority leads to obstacles in social interaction. On the one hand, because of physical and psychological defects, disabled children often encounter many setbacks during their growth, such as insufficient self-care ability, low learning efficiency, and low success rate. In the long run, disabled children are prone to inferiority. On the other hand, some disabled children are over-cared and protected from an early age and all aspects of their needs can be met at any time, easily leading to incorrect attitudes of selfishness and caprice. Under the above circumstances, disabled children are prone to self-enclosure, are unwilling to communicate with people around them and become introverted and isolated, which leads to obstacles in social interaction.

Second, hostility due to sensitivity leads to unhealthy mood and behavior. Disabled children are very sensitive because of their inner inferiority. The specific manifestation is that they are very concerned about the attitudes, words and behaviors of others, especially the evaluation of others. For positive evaluations, they may wonder if others are motivated by sympathy. For negative evaluations, they have strong mood fluctuations. Because disabled children lack mental "buffer" and "pressure reducing valve", they are prone to anger, causing them to clash with people when their self-esteem is challenged or hurt, which in turn makes them vulnerable to social exclusion.

Third, complaining about life due to pessimism leads to the lack of confidence and a negative attitude to life. Under the effect of inferiority and sensitive psychology, the outlook on life of disabled children is often pessimistic, which is reflected in "complaint" in behavior. They complain about the environment, relatives and friends, as well as destiny. Besides, they have a strong sense of incompetence and deprivation. Under such circumstances, disabled children often lack confidence, feeling that they are born with inferiority. They are not understood and are not willing to be in contact with people. Even if they are willing to do it, they are more passive and lack initiative and enthusiasm in manners of dealing with people, not to mention that they actively interact with others and integrate into society.

\subsection{Objective social factor}

First, laws and regulations are not sound enough and the right system is not perfect.

Since the founding of New China, after nearly 70 years of development, the Constitution, the Law on the Protection of Minors, and the Law on the Protection of Disabled People constitute the basic right system and protection mechanism for disabled children in China. However, there are still obvious deficiencies. In terms of legal content, the rights of disabled children are scattered among many laws and regulations and there is no specific law for disabled children. This kind of "interspersed" existence in form reflects "non-systematic" structure in content. From the perspective of legal practice, the protection of disabled children rights has not been paid high attention to by law enforcement agencies and judicial bodies. The rights of disabled children defined in the law are still far from the reality, lacking practical and feasible methods, which makes the subjective status of disabled children exist theoretically but missing in reality. [12]

Second, there is a bias in public cognition, and social concepts hinder social integration.

The macroscopic social structure and social concept depend on the structure and ideology of the social dominant group and also influence the living state and behavior pattern of the social subgroup. Due to the dual attributes of disability and children, the living conditions and behavioral patterns of disabled children are bound to be influenced by traditional social concepts. On the one hand, traditional social concepts have a tendency to stigmatize disabled people who are considered to be "morbid" and "burdensome". This non-receptive concept 
has greatly reduced the space for disabled people to share social material and cultural achievements. It also deprived them of their equal rights in politics, economy, culture, society, and ecology. On the other hand, the group of children has never been considered to have a sense of subjectivity and is often regarded as a parent's possession. If children do not have the opportunity to participate in comprehensive social life in their childhood, it is more difficult to participate in social life when they grow up [13]. Therefore, disabled children bear the double hindrance of social concepts and then the difficulty of social integration is conceivable.

Third, social interaction is out of place and cannot provide the necessary social support.

Each behavior subject lives in a certain social relationship. Different social relationships together constitute the individual's social network. The social network in turn gives the individual social support. This support can be material or spiritual. However, for disabled children, there is sometimes no possibility of social interaction and they are directly excluded from homes, schools, communities, and other places. For example, some families directly abandon disabled children. The sound students in ordinary schools have an aversion to disabled children, and there is a lack of corresponding social interaction fields in the community. Once disabled children are unable to socialize, they will have difficulty in obtaining social support from social networks. Not only will their socialization be seriously affected, but also the material and spiritual foundations needed for survival will be shaken.

\section{RELEVANT MEASURES AND SUGGESTIONS}

In order to find a suitable action measure for the social integration of disabled children, there must be a comprehensive and multi-angle analysis.

\subsection{Strengthening concept education and publicity to form a social fashion of caring for disabled children}

Morality, as a soft constraint in social life, reflects lofty pursuit. In social traditional concepts and discourse habits, "disability" is often associated with "waste", and disabled children with birth defects are even stigmatized as "divine punishment" and "retribution". When disabled children are considered abnormal, it becomes inevitable that they become marginal persons in their families and society. With the progress of society, the social concept of disabled children has been greatly improved, but there are still biases. Publicity department of our country should strengthen the construction of public culture so that the concept of "the disabled population is the embodiment of human diversity and difference in the development of human society" is deeply rooted in the hearts of the people. Thus, all kinds of biases against disabled children in the society are eliminated; Disabled children are respected, understood, and accepted by more people; A better environment for disabled children into society is created.

\subsection{Improving relevant laws and supporting systems to protect the rights of disabled children}

As a kind of hard constraint in social life, the law reflects the bottom-line thinking. Only by implementing the special legislation for the protection of disabled children as soon as possible and clarifying the rights of disabled children, can a solid "foundation" be laid. In terms of legal practice, it is necessary to formulate various supporting systems suitable for different conditions across the country, to clarify the government's responsibilities and to stipulate the main body of law enforcement, so as to protect the social participation rights and the right to education of disabled children.

Based on the Law of the People's Republic of China on the Protection of Disabled People, the construction of laws and regulations on rehabilitation, education and barrier-free facilities for disabled children should be strengthened and the Regulations on the Rehabilitation of Disabled Children, the Regulations on the Education of Disabled Children and the Regulations on the Construction of Barrier-free Facilities, etc. should be formulated. Besides, the social environment in which disabled children participate in social life should be improved to promote the social integration of disabled children.

\subsection{Relying on the achievements of Internet development to improve the information management of archives for disabled children}

The archival management of disabled children is the foundation of the relief work for disabled children, which is related to the basic living security and social welfare of disabled children and is an important basis for protecting the rights of disabled children. With the deepening of the Internet era, the information management of archives for disabled children combined with big data analysis and other means can play an increasingly important role.

The information management of archives for disabled children can integrate the powers of departments and organizations such as education, health, and the Disabled Persons' Federation. It can use Internet technology to concentrate information on the occurrence, intervention, education, and rehabilitation of disabled children who belong to different departments and form a relatively complete, timely and accurate national unified data management system for disabled children's information archives. Once the personal information of disabled children is connected to the system, the whole process of accepting various services during their growth is recorded, so that each department can grasp the service needs of disabled children and provide follow-up, rehabilitation, 
education, and other tracking services at any time. It can also provide a basis for decision-making by government departments.

\subsection{Social work intervention to strengthen community rehabilitation management for disabled children}

As a kind of service activity, social work can help difficult groups prevent and solve some social problems. Social workers, as service providers, policy advocates, organization managers, and educators, can integrate social resources and provide targeted services for disabled children as well as improve the living environment for the disabled children. Social work can be introduced through community recruitment or government purchase.

At present, the rehabilitation work of disabled children is not perfect. Rehabilitation institutions are faced with survival problems and rehabilitation services cannot meet the needs of rehabilitation. As the basic environment in which disabled children live, the community is a key link in the smooth integration of disabled children into society. First, the community management system should be improved, which is guided by the government and directed by the Disabled Persons' Federation. The characteristics of rehabilitation work should be highlighted, and the rehabilitation work system should be improved. Next, funding should be increased to cultivate professional rehabilitation institutions and to hire experienced rehabilitation personnel. Finally, the management system of community workers should be improved. Social worker training should be done well and the work evaluation system should be established.

\section{CONCLUSION}

This study set out to improve the support system to disabled children in regard to their social integration. By summarizing theoretical achievements about social support for children with disabilities, this study has initially explored relevant solutions that are suitable for China's current conditions and tendency of development to help disabled children to integrate to the society from four aspects: morality, legal system, network, and community: 1) the understanding and caring to disabled children from the general population are crucial and essential, therefore raising majority's awareness to form a social fashion that considers the disabled by strengthening the education and publicity is the first step; 2) legal system as one of the most important components that bind and form citizens' mind and behavior should be improved to support and protect disabled children; 3 ) in light of the enormous while scattered population of the disabled, the internet should be taken advantage to manage and support disabled children efficiently by creating an online archives; 4) communities connect tightly to people's daily life, hence, the community rehabilitation management for disabled children should be established with social work intervention.

\section{ACKNOWLEDGMENT}

My deepest gratitude goes first and foremost to all the staff of Chengdu Child Rehabilitation Center, for their cooperation and wise comments. The patience and kindness displayed by them not only during the writing of this thesis but also during the treatments of those disabled children give me constant encouragement and motivation. Besides, I would like to thank my beloved parents and friends, for their considerations and great support in me all through these years. Without their consistent company and caring, this thesis would have not reached its present form.

\section{REFERENCES}

[1] The National Statistics Bureau \& the Leading Group for the Second National Sample Survey of Disabled People. The Communique on Main Data of the Second National Sampling Survey of Disabled People, 2007. http://www.stats.gov.cn/tjsj/ndsj/shehui\%20/2006/html/fu3 .htm.

[2] An Hongtao \& Zhu Mei. On the Compensatory Educational Function of Community Activities for the Social Development of Disabled Children [J]. Journal of Zaozhuang University, 2015(3): 108.

[3] Xie Tao \& Xie Qinghua. Research on Disabled Children from the Perspective of Social Exclusion Theory [J]. Research on Disability, 2014(3): 17.

[4] Xu Limin. Analysis of the Concept of "Social Integration" [J]. Academia, 2014(7): 85.

[5] Liu Lin \& Li Fan (Editor-in-Chief). Guidelines for Social Integration of Disabled People and Their Communities [M]. Beijing: Huaxia Publishing House, 2010: 11

[6] The main method of participatory development is based on community by means of external intervention, centering on the construction of the autonomous management and management ability of the community and initiating self-development mechanism of the community 
[7] Zou Jingwei. Summary of Social Integration Project for Disabled People in "Sunshine Angels" [J]. Changchun University of Technology, 2014(6).

[8] Liu Yali. Study on the Construction of Social Support Network for Social Work Intervening Disabled Children_-Taking Small "W" as an Example[J]. Central China Normal University, 2017: 1.

[9] Xu Qiaoxian. Difficulties and Solutions for Social Integration of Disabled People from the Perspective of Social Inclusion [J]. Xue Hai, 2012(6): 63.

[10] An Hongtao \& Zhu Mei. On the Compensatory Educational Function of Community Activities for the Social Development of Disabled Children [J]. Journal of Zaozhuang University, 2015(3): 108.

[11] Wang Jia. Psychological Health Education for Children with Mental Disabilities [J]. Academy, 2012(22): 130.

[12] Xu Qiaoxian \& Ding Yong. On the Formation and Development of the Rights of Disabled Children [J]. China Special Education, 2014(9): 18.

[13] Xie Tao \& Xie Qinghua. Research on Disabled Children from the Perspective of Social Exclusion Theory [J]. Research on Disability, 2014(3): 18. 